\begin{tabular}{|c|c|c|}
\hline 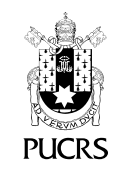 & $\begin{array}{l}\text { ESCOLA DE } \\
\text { HUMANIDADES }\end{array}$ & $\begin{array}{l}\text { Revista Digital do Programa de Pós-Graduação em Letras da PUCRS } \\
\text { Letrônica, Porto Alegre, v. 13, n. 1, p. 1-14, jan.-mar. } 2020 \\
\text { e-ISSN: 1984-4301 }\end{array}$ \\
\hline de) $\mathrm{http}: / / \mathrm{dx}$ & $\mathrm{rg} / 10.15448 / 1984-4301.2020 .1 .35160$ & \\
\hline
\end{tabular}

\title{
As biografias de Manuela Sáenz: Um embate de memórias, vozes e discursos
}

\author{
Manuela Sáenz's biographies: A clash of memories, voices and discourses \\ Las biografías de Manuela Sáenz: Un embate de memorias, voces y discursos
}

\author{
Rosane Cardoso ${ }^{1}$ \\ orcid.org/0000-0002-8471-307X \\ rosanemc@unisc.br
}

Recebido em: 1 ago. 2019.

Aprovado em: 4 out. 2019.

Publicado em: 7 abr. 2020.
Resumo: Manuela Sáenz de Thorne é geralmente lembrada por sua ardente história de amor com Simón Bolivar, o Libertador. Ativista e influente antes e depois de sua relação com Bolivar, Manuela morre sozinha e falida em Paita, Peru. Este artigo destaca, além da importância política Manuela Sáenz, seu exilio e o legado que se evidencia, na atualidade, em inúmeras referências literárias, audiovisuais e biográficas, produções que tanto mantêm a imagem da mulher movida pela paixão, quanto destacam a lider revolucionária à frente do seu tempo. Este estudo concentra-se, portanto, nas várias biografias de Manuela Sáenz. A partir desse olhar, considera-se o papel que determinadas memórias construiram a respeito da "Insepulta de Paita".

Palavras-chave: Manuela Sáenz. História. Memória. Narrativa.

Abstract: Manuela Sáenz de Thorne is commonly remembered for her passionate love story with Simón Bolivar, The Liberator. Although Manuela was an activist and an influential person before and after her relationship with Bolivar, she died alone and bankrupt in Paita, Peru. This paper highlights Manuela Sáenz's political influence, as well as the period of exile and the legacy, which is currently evidenced in a variety of literary, audiovisual and biographical references. In general, these productions maintain her image as a woman who was moved by passion and emphasize the character of a revolutionary leader ahead of her time. Therefore, this study focuses on the multiple biographies of Manuela Sáenz. From this perspective, we consider the role that certain memories have built about the "Insepulta de Paita".

Keywords: Manuela Sáenz. History. Memory. Narrative.

Resumen: Manuela Sáenz de Thorne es generalmente recordada por su ardiente historia de amor con Simón Bolivar el Libertador. Activista e influyente antes y después de su relación con Bolivar. Manuela muere sola y en bancarrota en Paita, Perú. Este artículo destaca, además de la importancia política de Manuela Sáenz, su exilio y el legado que es evidente hoy en numerosas referencias literarias, audiovisuales y biográficas, producciones que mantienen a la vez la imagen de la mujer movida por la pasión y la de líder revolucionaria para allá de su tiempo. Por consiguiente, este estudio se centra en las diversas biografias de Manuela Sáenz. Desde este punto de vista, se considera el papel que determinadas memorias han construido sobre la "Insepulta de Paita".

Palabras clave: Manuela Sáenz. Historia. Memoria. Narrativa.

"Para que inventar histórias quando a realidade já é tão extraordinária?". (Nancy Houston) 


\section{Introdução}

A história do processo de independência da América não pode ser contada sem que seu maior herói seja lembrado. Simón José Antonio de La Santísima Trinidad Bolivary Palacios PonteAndrade y Blanco (1783-1830) nasceu na alta elite criolla. Sua família era uma das mais ricas de Caracas, Venezuela, com fazendas que cultivavam cacau, algodão, anil, cana-de-açúcar e café, além possuir extensa propriedade de mineração na região de Aroa y San Marcos. Descendente direto de antigos colonizadores espanhóis, chegados à América, no século XVI, seu destino previa que fosse estudar na Europa, como o pai. No entanto, as mortes prematuras do pai, em 1786, e da mãe, em 1792, mudaram esses planos e Simón Bolivar iniciou seus estudos em escolas caraquenhas. Posteriormente, foi educado por preceptores, entre eles Andrés Bello e Simón Rodríguez.

Apesar de Bello já ser um filólogo e poeta reconhecido na época, o menino recebeu maior influência de Rodriguez, partidário das ideias de Jean-Jacques Rousseau, que acompanhou o jovem na sua formação na Europa. Aos 14 anos, Simón ingressou na vida militar. Casou-se, em Madri, com Maria Teresa Rodriguez de Toro y Alayza, também pertencente à elite criolla de Caracas, em 1802. O casal retornou à Venezuela, onde a jovem faleceu meses depois, devido à febre amarela. Bolivar, então, regressou à Europa, em 1803, a fim de aprofundar "seus conhecimentos e ampliando os contatos com figuras representativas do mundo científico europeu" (BELLOTTO; CORRÊA, 1983, p. 11). Entre 1806 e 1807, visitou os Estados Unidos, retornando, a seguir, a Caracas, onde passou a administrar os bens herdados. Mas logo se destacou por sua liderança politica e esteve à frente da primeira investida para a união das nações independentes da América Latina, a Grã-Colômbia.

Firme no propósito de apoiar a descolonização, Bolivar foi essencial para a libertação da América
Espanhola. Visionário e estrategista, levou Bolívia, Colômbia, Equador, Panamá, Peru e Venezuela à independência. Ainda que nem tudo em seu caráter possa ser considerado virtuoso, dificilmente seu papel como "El Libertador" é contestado. Ao longo dos tempos, desde a morte prematura aos 46 anos, pobre e doente, seu nome nunca foi esquecido e tem sido mote de biografias, romances e narrativas audiovisuais. No entanto, nem o homem, nem o herói estão sozinhos no processo de mitificação. A ele se liga, de maneira indelével, a figura de Manuela Sáenz.

Durante muito tempo, as narrativas, inclusive as históricas, citavam Manuela como a companheira, algo exótica, de Simón Bolivar. Porém, pesquisas mais abrangentes e o crescimento dos estudos de gênero evidenciaram, aos poucos, o papel decisivo que Sáenz desempenhou na luta pela independência da América Latina. A historiadora Pamela Murray (2008) se pergunta se Manuela teria alcançado tal proeminência sem Bolivar. Provavelmente não, mas está claro que Sáenz sempre esteve longe de ser alguém comum.

Nessa linha, María José Vilalta (2012) comenta que muitos heróis tiveram esposas e amantes. Bolivar, inclusive, envolveu-se com várias mulheres². Contudo, nenhuma ficou para a história. Com esse argumento, Vilalta chama a atenção para a construção da história de mulheres, revisando as manipulações da memória sobre a presença feminina, tanto em sociedades históricas, quanto na contemporaneidade. Manuela Sáenz é um exemplo emblemático dessa situação.

Conforme Jelin (2012), no processo de construção das memórias, o esquecimento e o silêncio ocupam um lugar central. Como a memória absoluta é impossivel, toda a memória é seletiva. Contudo, existe uma multiplicidade de situações nas quais esses esquecimentos e silêncios se manifestam, com usos e sentidos diversos. A historiadora referese principalmente a situações traumáticas. Mas, considera-se que o mesmo se aplica à memória biográfica, no que respeita a Manuela Sáenz.

\footnotetext{
2 Sobre esse tema, Ramón Urdaneta escreve, em 2003, Los amores de Simón Bolivary sus hijos secretos. No estudo, Urdaneta lista quase trinta mulheres e contabiliza vinte filhos do Libertador. Em 2014. Eduardo Lozano Torres publica Bolivar, un empedernido mujeriego. Já o psiquiatra colombiano Mauro Torres estuda a conduta sexual de Simón Bolivar a partir da teoria das compulsões. Em 2007, publica Las grandes compulsiones, obra que se dedica ao estudo de Bolivar, Dostoievski, Hitler, Freud, entre outras personagens históricas consideradas compulsivas.
} 
Os textos sobre Manuelita ${ }^{3}$ são muitos. Neste artigo, são apresentados apenas algumas produções, a fim de delinear uma história das biografias da revolucionária quitenha. Considera-se esse volume de obras como uma grande narrativa, um romance, se se quiser. Para justificar essa perspectiva, podemos nos abeberar em Georg Luckács (2000) que vê o romance como a única possibilidade de a literatura trazer a valorização da experiência do sujeito. Reconhecendo a arte como essencial para captar o homem - e, por consequência, a sociedade - a transgressão do autor é antes uma licença à biografia em favorecimento a um modo pessoal de falar sobre a vida, mesmo que não seja a sua, pois as memórias, assim como as identidades, pondera Jelin (2012, p. 58), não são coisas sobre as quais pensamos; são coisas com as quais pensamos.

\section{Nasce um mito... e é mulher}

Manuela Sáenz de Thorne (1797-1856) nasceu em Quito, Equador. Os pais eram o fidalgo espanhol Simón Sáenz de Vergara e uma rica criolla chamada María Joaquina de Aizpuru. Apesar do nascimento de sangue nobre, seus pais não eram casados, o que causou a exclusão da mãe do seio familiar e, com o tempo, a levou à morte ${ }^{4}$. Manuela, no entanto, não foi abandonada. Mesmo sendo um homem casado, Sáenz de Vergara assumiu a filha, dando-lhe uma educação esmerada, enquanto era mantida em ótimos internatos. Houve um período, inclusive, em que a jovem morou com a familia paterna. A vida de interna de Manuelita não foi trágica ou difícil. Sinceramente amada pelas freiras, teve uma infância e início de juventude tranquilos. Por volta dos dezesseis anos, fugiu com o jovem oficial Fausto D'Elhuyard. Pouco se sabe sobre essa aventura, além do fato de haver acabado rapidamente.
Em 1817, seu pai a casou com o comerciante inglês James Thorne, décadas mais velho do que ela. O casamento permitiu a Manuela inúmeras viagens entre Quito e Lima, devido às transações comerciais do marido e foi na capital peruana que ela iniciou suas atividades independentistas. Em 1822, o General San Martín outorgou-lhe a condecoração "Caballeresca de La Orden del Sol". No mesmo ano, conheceu Simón Bolívar e abandonou Thorne.

Manuela viveu inúmeras peripécias ao lado de Bolivar, inclusive salvando a vida do amante. Quando o herói faleceu, no entanto, ela foi obrigada a exilar-se, mesmo tendo prestado serviços importantes para a independência. Francisco de Paula Santander ${ }^{5}$ a expulsou de Nueva Granada 6 , confiscando todos os seus bens. Manuela Sáenz havia se tornado a imagem da subversão e um perigo para os inimigos de Bolivar. Na Jamaica, encontrou apoio e ali permaneceu até retornar ao Equador, em 1835.

Mais uma vez expulsa - e depois de buscar refúgio em vários lugares -, instalou-se no Porto de Paita, Peru. Ali, Manuela viveu os próximos 21 anos em situação econômica precária. Mas, ainda que o seu marido tenha tentado a reconciliação e o seu país de origem, permitido seu regresso, ela recusou ambos. Durante o exilio, recebeu as visitas de Giuseppe Garibaldi, Herman Melville, Simón Rodríguez e González Prada.

Em 1856, contraiu difteria. Àquelas alturas, a sua saúde já estava prejudicada por uma queda sofrida logo que chegou a Paita. Esse acidente a manteve em uma cadeira de rodas. Quando faleceu, o seu corpo e os seus pertences foram incinerados a fim de evitar que a população se contaminasse. Infelizmente, além da morte trágica, junto com o corpo de Manuela Sáenz, também foi queimada extensa parte da correspondência entre ela e Simón Bolivar.

Em reportagem apresentada por Gonzalo

\footnotetext{
3 Manuela Sáenz também é conhecida como Manuelita Sáenz, Manuelita, Libertadora del Libertador, La Generala, La Coronela e, no campo poético, como La insepulta de Paita.

4 Não há dados precisos sobre o contexto da morte de María Joaquina Aizpuru.

5 Francisco José de Paula Santander (1792-1840): jurista, revolucionário, militar e político colombiano, considerado o "Libertador de Colombia". Foi o quarto presidente do país. Paula Santander e Bolivar divergiam quanto à forma de governo defendida.

6 Denominação dada a uma jurisdição colonial da Espanha em 1717. O território compreendia ao Panamá, Colômbia, Equador e Venezuela (no contexto atual).

7 Não há registros de que o encontro entre Manuela e Melville tenha, de fato, ocorrido. Esse "dado" aparece na obra de Van Hagen (1952).

8 José Manuel de los Reyes González de Prada y Álvarez de Ulloa (1844-1918): poeta, anarquista ensayista y pensador peruano.
} 
Higueras a Rudy Medonza (2014), é visível a influência exercida pela exilada na vida cotidiana das pessoas de Paita, mesmo nos dias de hoje. A reportagem baseou o livro de Higueras, El último Tallán, onde, mais uma vez, Manuela Sáenz aparece como personagem imprescindivel da vida e da história da América. Ainda assim, não são poucos os relatos que denunciam a possivel falácia sobre o último descanso de La Generala. Um dos tantos mistérios que a cercam é que seu corpo ainda está em Paita. Para Walter Márquez (2010), historiador, professor de História na Universidad de Los Andes, o boato trata-se de um golpe publicitário que se aproveita do fato de os restos jamais terem sido encontrados. Ele se utiliza dos famosos versos de Neruda, La insepulta de Paita, para "provar" que Manuela Sáenz descansa em terras peruanas.

Mover-se pela biografia de Sáenz exige o estabelecimento de critérios, a fim de discernir o que realmente se deseja destacar a respeito dessa personagem. Manuelita transita entre história e ficção, mito e reivindicação política, razão para o desabafo de Márquez․ Amante, ninfomaniaca, adúltera, filha de origem espúria, guerrilheira, revolucionária, exilada. Não faltaram adjetivos para apresentá-la. Houve, também, quem quisesse ignorar a sua existência. Em 1883, no centenário de nascimento de Simón Bolivar, o governo da Venezuela organizou portentosa obra sobre o Libertador. No entanto, os trechos que colocavam Manuela ao lado do herói foram suprimidas, sob a alegação de que tais aventuras diminuiriam a imagem do Libertador (SÁENZ, 2010, p. 10).

$O$ intento moral, felizmente, foi em vão. Embora a edição completa dos manuscritos somente viesse à luz em 1914 - fora da Venezuela -. outros livros consideraram impossivel elidir a presença de Manuela e o número de biografias ou referências feitas a ela só cresceu. No entanto, a revolucionária continua ofuscada pela imagem da mulher que ama, em detrimento à mulher que, antes e depois da sua grande aventura com Bolivar, teve papel de guerrilheira e de lider inconteste em defesa da autonomia da América.

A mitificação sobre a qual hoje não restam dúvidas, não se deu sem insistentes tentativas de apagá-la da história, sobretudo no Equador e na Venezuela, onde, de acordo com Grillo, "seu nome foi apagado da historiografia e da memória coletiva" (GRILLO, 2015, p. 68, tradução nossa) ${ }^{10}$. Von Hagen (1952) corrobora esse apagamento:

\begin{abstract}
Como, então, todos os primeiros registros escaparam dos biógrafos? Por que, neste século após a morte de Bolivar, ninguém os encontrou? A resposta - e é uma resposta - está na personalidade de Manuela. Quando Simon Bolivar foi metamorfoseado em semideus pelas mesmas pessoas que dez anos antes o haviam execrado, Manuela Saénz, segundo os historiadores, teve de abrir caminho para o mito. Todos os detalhes de sua vida foram oficialmente suprimidos, os documentos que a mencionavam desapareceram e seus últimos vinte anos foram vividos na obscuridade em Paita. E então, para completar a imolação, quase todas as emocionantes cartas de amor que ela trocou com Bolivar foram destruídas após sua morte durante a epidemia da difteria. Por mais de meio século, os historiadores mantiveram o seu acordo de cavalheiros - Manuela nunca foi mencionada (VON HAGEN, 1952, p. 302, tradução nossa). ${ }^{11}$
\end{abstract}

O mesmo não ocorreu na Colômbia e no Peru, países em que Jean-Baptiste de Boussingault e Ricardo Palma, respectivamente, dedicaram-se a escrever sobre Sáenz. Ainda assim, os relatos de ambos deixam transparecer a dificuldade de compreender uma mulher a quem consideravam, às vezes, extremamente feminina e sensual e, outras, masculinizada e agressiva, como pode-se perceber em Tradiciones peruanas (1863), de Palma:

\footnotetext{
9 A análise e a crítica de Walter Márquez, ex-parlamentar venezuelano, na época, estavam diretamente ligadas à sua luta contra o governo de Hugo Chávez, responsável, junto com o governo do Equador, pelo livro-homenagem Manuela Sáenz: pasado, presente y futuro. 10 Do original: Su nombre fue borrado de la historiografia y de la memoria colectiva.

11 Do original: How then did all the early records escape biographers? Why in this century following Bolivar's death had not someone found them? The answer - and it is an answer - lies in the personality of Manuela. When Simon Bolivar was metamorphosed into a demigod by the very people who ten years before had execrated him, Manuela Saenz, it was willed by the historians, had to go to make way for the myth. All details of her life were officially suppressed, documents which mentioned her disappeared, and her own last twenty years were lived in obscurity in Paita. And then, to complete the immolation, almost all the stirring love letters she exchanged with Bolivar were destroyed after her death during the diphtheria epidemic. For more than half a century the historians kept their gentleman's agreement - Manuela was never mentioned.
} 
Desde aquela tarde encontrei em Paita um atrativo e nunca fui à terra sim passar uma horinha de saborosa conversa com dona Manuela Sáenz. Recordo também que quase sempre me obsequiava com doces feitos por ela mesma em um braseiro de ferro que fazia colocarem perda da poltrona.

Era uma senhora abundante de carnes, olhos negros e animadíssimos, [...] mão aristocrática [...] na entonação dessa senhora, havia algo de mulher superior acostumada a mandar e a fazer valer a sua vontade. Era um perfeito tipo de mulher altiva. Sua fala era fácil, correta e nada presunçosa, predominando nela a ironia. [...]

Dona Manuela era um equivoco da natureza que, em formas esculturalmente femininas, encarnou espirito e aspirações varonis. Não sabia chorar e sim encolerizar-se como os homens de caráter duro. [...] Encontrava como seu eixo em meio à turbulencia dos quartéis e do acampamento. [...] foi vista nas ruas de Quito e nas de Lima cabalgando à maneiro dos homens em brioso corcel, escoltada pelos lanceiros colombianos e vestindo um dólmã vermelho e bombachas de algodão brancas. Sáenz renunciava a seu sexo. [...] Sáenz foi a mulher-homem (GRILLO, 2015. p. 69-70, tradução nossa). ${ }^{12}$

Boussingault, ao escrever suas Memorias (1892), dedica um capítulo inteiro a Manuela, "El salto de Tequendama: história de Manuela Sáenz". Como Grillo bem nota, sua perspectiva é eurocêntrica e masculina:

Sua maneira de ser era bem incompreensivel; podia comportar-se como uma dama ou como uma "ñapanga ${ }^{13}$ "qualquer; dançava com igual perfeição o minuet e a cachuca (o can can). Sua conversa não era interessante, quando deixava os adornos galantes; era brincalhona, mas carecia de graça. [...] em Lima, Manuelita foi de uma inconsequência incrivel; tornou-se uma Messalina e os criados me contaram coisas insólitas: o único que as ignorava era o general Bolivar. Os amantes, quando estão bem enamorados, são tão cegos quanto os maridos.

[...]

Ela dera provas de sua coragem militar; ao lado do general Sucre, ajudou, lança na mão, na batalha de Ayacucho, o último encontro entre americanos e espanhóis [...]. Pode-se dizer que ele teve treinamento, do que não há dúvida, mas Manuelita, como você verá, foi dotada de grande valentia, sangue frio e calma incriveis, nas circunstâncias mais perigosas (GRILLO, 2015, p. 72-73, tradução nossa). ${ }^{14}$

Boussingault, assim como Palma, constrói duas Manuelas, sem conseguir relacioná-las em um âmbito mais humano. Ela é dividida pelo comportamento que o(s) autor(es) considera(m) adequada ou não. Ela é degradada quando se destaca como ela mesma, demonstrando poder - e esse poder, na citação das Memorias, é só o de "fêmea" - e é exaltada quando dá provas do seu valor militar, papel que desagrada a Palma. De certo modo, ambos asseveram o que foi "constatado" por Alfonso Rumazo González, na biografia Manuela Sáenz, la libertadora del libertador:

Nasce do adultério e no adultério ela mesma viverá durante os melhores anos de sua vida. Além disso, vive em tempos em que o adultério e outras concupiscências são o comportamento normal, elegante e bem aceito entre a aristocracia e entre os criollos de todas as classes (SÁENZ, 2010, p. 19).15

\section{Esses discursos sobre Manuela permitem notar} o quanto ela esteve, por muito tempo, relegada ao papel de amante e mesmo de "louca da casa" na história da América Latina. O olhar sobre ela, no que tange aos três biógrafos oitocentistas, denota um olhar determinista. Seus pais faziam parte da

\footnotetext{
12 Do original: Desde aquella tarde encontré en Paita un atractivo, y nunca fui a tierra sin pasar una horita de sabrosa plática con doña Manuela Sáenz. Recuerdo también que casi siempre me agasajaba con dulces hechos por ella misma en un braserito de hierro que hacía colocar cerca del sillón. [...] Era una señora abundante de carnes, ojos negros y animadísimos, [...] mano aristocrática [...] En el acento de la señora había algo de mujer superior acostumbrada al mando y a hacer imperar su voluntad. Era un perfecto tipo de la mujer altiva. Su palabra era fácil, correcta y nada presuntuosa, dominando en ella la ironía. [...] Doña Manuela era una equivocación de la naturaleza, que en formas esculturalmente femeninas encarnó espíritu y aspiraciones varoniles. No sabía llorar sino encolerizarse como los hombres de carácter duro. [...] Se encontraba como en su centro en medio de la turbulencia de los cuarteles y del campamento. [...] Se la vio en las calles de Quito y en las de Lima cabalgada a manera de hombre en brioso corcel, escoltada por dos lanceros de Colombia y vistiendo dolmán rojo y pantalón bombacho de cotonía blanca. La Sáenz renunciaba a su sexo. [...] La Sáenz fue la mujer-hombre.

13 Ñapanga denomina la mujer mestiza o mulata del sur de Colombia y de la región de Quito, Ecuador.

14 Do original: Su manera de ser era bien incomprensible; tan pronto lucía como una gran señora, o como una "ñapanga" cualquiera; bailaba con igual perfección el minuet o la "cachuca" (el cancán). Su conversación no tenía ningún interés, cuando se salía de los adornos galantes: era burlona, pero carecía de gracia. [...] En Lima Manuelita había sido de una inconsecuencia increible; se convirtió en una Mesalina y los edecanes me contaron cosas insólitas: el único que las ignoraba era el general Bolivar. Los amantes, cuando están bien enamorados, son tan ciegos como los maridos. [...] Ella había dado pruebas de su valor militar; al lado del general Sucre, asistió lanza en mano, a la batalla de Ayacucho, último encuentro que tuvo lugar entre americanos y españoles [...]. Se puede decir que tenia entrenamiento, de lo cual no cabe duda pero Manuelita, como se va a ver, estaba dotada de gran valor, de sangre fría y de una calma increibles, en las circunstancias más peligrosas. 15 Do original: Nace de adulterio y en adulterio vivirá ella misma los mejores años de su vida. Llega además en tempos en que el adulterio y otras concupiscencias son lo normal, lo elegante, lo muy perdonado entre la aristocracia y entre los criollos de todas las clases.
} 
elite, mas Manuela era filha bastarda, marca que frequentemente parece justificar, aos olhos de seus estudiosos, sua atitude indômita. De bom grado, a História a teria apagado. Manuela, porém, sempre foi uma espécie de ruído, alguém que, mesmo sem receber o devido reconhecimento, exigia atenção. Não escapa à análise o fato de não ter tido filhos, pelo fato de ser estéril, ou "machorra", como se costumava dizer naqueles tempos. Com isso, sua liberdade sexual torna-se apenas isso: desejo por sexo.

Nessa linha, não passa despercebida a imagem inúmeras vezes atribuida à Manuela como promíscua, ou "Mesalina", segundo Boussingault. Todos os estudos referidos neste artigo remetem direta ou indiretamente, com ou sem juizo de valor, à naturalidade com que Sáenz se expressava sexualmente. Na compilação Las más hermosas cartas de amor entre Manuela y Simón (TAMARIS; AÑON, 2010), é visivel que a ela não envergonham palavras de desejo por seu amante, conforme demonstram trechos de suas cartas:

Em meus pensamentos, estou mais do que convencida de que você é o amante ideal e sua lembrança me assombra o tempo todo. Pensei que, satisfazendo os meus caprichos, inundaria meus sentidos, mas sou incapaz de me satisfazer, pois é você que eu preciso; não há nada que se compare ao impulso do meu amor (TAMIRIS; AÑON, 2010, p. 46, tradução nossa). ${ }^{16}$

Agora você dirá que sou libidinosa por tudo que vou the contar: que me beije toda, como me deixou acostumada. [...] Você não vê? Eu pergunto, por que ele me deixou apaixonada? Com a alma em pedaços! Você diz que o amor liberta. Sim, mas juntos. Isso foi comprovado em Junín; caso contrário, sinto-me presa na minha inquietação (TAMIRIS; AÑON, 2010, p. 52, tradução nossa). ${ }^{17}$

No entanto, essas cartas, bem como os diários, conferem outro aspecto à mitificação de Sáenz. Como diz Sarlo, encontrar um diário inédito pode ser a perdição de um historiador, pois é demasiado belo para ser real (SARLO, 2013). Depois de longo esquecimento, textos atribuidos à Manuela, como Las más hermosas cartas de amor entre Manuela y Simón (TAMARÍS; AÑON, 2010), Diario de Paita e Los diarios perdidos de Manuela Sáenz y otros papeles (ÁLVAREZ SAÁ, 2005), são encontrados, compilados e dão novo sentido à personalidade da heroína. Mas também provocam controvérsia sobre onde termina a História e começa a ficcionalização.

\section{A memória entre a história e a ficção}

No campo de obras mais recentes a respeito de Manuela Sáenz, alguns titulos claramente priorizam o papel que ela teve como amante de Bolivar: Manuela Sáenz: la divina loca (BRICEÑO, 1967), La Libertadora del Libertador (RUMAZO GONZÁLEZ, 1944); The four seasonsof Manuela: a biography the Love story of Manuela Saenzand Simon Bolivar (VON HAGEN, 1958), traduzido, em 1958, para La amante inmortal; La caballeresa del sol, el gran amor de Bolivar (DEMETRIO AGUILERA-MALTA, 1964); La mujer providencia de Bolivar (HUMBERTO MATA, 1972), Manuela Sáenz, el último amor de Bolivar (MERCEDES BALLESTEROS, 1976), La esposa Del Doctor Thorne (1988), pseudo biografia amorosa de Manuela Sáenz, entre vários outros.

Para a embaixada equatoriana,

Manuela foi mulher, amante, companheira, amiga, guerreira, estrategista, cúmplice, dissimulada, coronel, general, dama do sol... bordadeira, deusa que embalava os sonhos e as realidades do amor e da liberdade (EMBAJADA DE LA REPÚBLICA DEL ECUADOR, 2011, p. 13. tradução nossa). ${ }^{18}$

Embora esse conjunto de epítetos enalteça a imagem de Manuela, ele também evidencia a tendência a emparelhar cada imagem de grandeza pessoal a uma referência a Bolivar. Para Añazco, não há dúvidas sobre o preconceito sofrido por Sáenz ao longo de toda a sua trajetória histórica no próprio país:

\footnotetext{
16 Do original: En mis pensamientos estoy más que convencida de que usted es el amante ideal, y su recuerdo me atormenta durante todo el tiempo. Encuentro que satisfaciendo mis caprichos se inundan mis sentidos, pero no logro saciarme, en cuanto a que es usted a quien necesito; no hay nada que se compare con el impetu de mi amor.

17 Do original: Ahora dirá usted que soy libidinosa por todo lo que voy a decirle: que me bese toda, como me dejó enseñada, ¿No lo ve? ¿Cómo me las arreglaré sin la presencia de usted? Pregunto, ¿Por qué me ha dejado enamorada? iCon el alma en pedazos! Usted dice que el amor nos libera. Sí, pero juntos. Eso fue comprobado por lo de Junín; de lo contrario me siento encarcelada en mi desasosiego.

18 Do original: Manuela fue mujer, amante, compañera, amiga, guerrera, estratega, cómplice, encubridora, coronela, generala, caballeresa del sol... bordadora, tierna hacedora que acunaba los sueños y las realidades del amor y de la libertad.
} 
Pode-se afirmar, sem medo de errar, que o Equador não valorizou, em sua real dimensão, a imensa contribuição política que Manuela deu para a libertação do domínio espanhol; traí-la para quem deveria ser sua filha favorita, o que é ratificado quando, ao estudar a história do Equador, ela é conhecida apenas como a amante do Libertador. Mas ela, como o sol que desaparece ao entardecer para parecer radiante pela manhã, aparece hoje, depois de séculos, limpida e lutadora como sempre (AÑAZCO, 2005, p. 165, tradução nossa). ${ }^{19}$

André (2013) vem estudando esse fenômeno de redução do papel de Sáenz que, por um lado tornou-se um mito literário inconteste e, por outro, uma simples seguidora de Bolivar. Mas isso também é o que vemos nas narrativas romantizadas, principalmente nas audiovisuais.

Uma boa história sempre vende bem e as aventuras de Manuelita e Simón são uma fonte infinita de impacto junto aos consumidores. Em Manuela Sáenz: la libertadora del libertador (2000), o apagamento da personagem se repete, apesar de ser a protagonista. Diego Rísquez reproduz a imagem sofrida da amante do General que, ao receber a visita de Herman Melville em Paita, reconstitui, para ele (ao longo de uma hora e meia de filme), a história de Bolivar. Portanto, mesmo que a presença de Sáenz tenha se intensificado na atualidade, continuamos a vê-la como uma sombra da glória bolivariana. Para Quintero:

Apesar de ter sido anunciado como um exercicio de desmitificação de Manuela, ele (Risquez) está contente em oferecer Manuela como um apêndice do grande homem da América e não como ela era: uma mulher por quem a paixão pela politica era a razão fundamental de sua existência, antes e depois do libertador (QUINTERO, 2000, p. 6, tradução nossa). ${ }^{20}$

Em 2001, o documentário Manuela Sáenz: a paixão de Simón Bolivar, apresentado por um canal que atende ao viés historiográfico, não hesitou em anunciar que o filme apresenta "a mulher por trás do libertador", capaz de desafiar as convenções da época para viver um grande amor. Apresentada como inteligente e corajosa, o documentário sublinha o quase total desconhecimento do público em relação a ela, assim como o apagamento do nome de Manuela dos Livros oficiais. Ainda assim, prevalece a imagem da amante.

A recentíssima série Bolivar (2019) tem 60 episódios, com cerca de uma hora cada, e é produzida com apuro formal e cuidado com o aspecto histórico, apesar das necessárias adequações ficcionais. Como o título denota, a trama se concentra na trajetória de Bolivar e o faz minuciosamente, prolongando-se na sua infância e no modo como o caráter heroico de Bolivar vai se constituindo. A bionovela dá certa ênfase ao marido de Manuela, James Thorne. Sáenz, interpretada pela atriz equatoriana Shany Nadan, é uma força importante na narrativa e sua influência na revolução é destacada, ainda que sem jamais se sobrepor ao herói inconteste da narrativa, o que é coerente com a proposta narrativa.

No campo literário, merece atenção a presença de Manuela na poesia, como no caso de "La insepulta de Paita", escrito em 1967, por Pablo Neruda, quase uma épica sobre a mulher cujo corpo insepulto ${ }^{21}$ permanece um mistério:

\author{
En Paita preguntamos \\ por ella, la Difunta: \\ tocar, tocar la tierra \\ de la bella Enterrada \\ No sabian. \\ [...] \\ Detuve al niño, al hombre,
}

al anciano,

y no sabian dónde

falleció Manuelita,

ni cuál era su casa,

\footnotetext{
19 Do original: Se puede afirmar, sin temor a equivocarnos, que el Ecuador no ha valorado, en su real dimensión el inmenso aporte político que dio Manuela para la liberación del dominio español; traicionándola asi a quien debía ser su hija predilecta, lo cual se ratifica cuando al estudiar la historia del Ecuador, únicamente, se la conoce como amante del Libertador. Pero ella, como el sol que desaparece al atardecer para lucir radiante a la mañana, así aparece hoy, después de siglos, límpida y luchadora como siempre.

20 Do original: Pese a anunciarse como un ejercicio de desmitificación de Manuela, se conforma con ofrecernos a Manuela como apéndice del grande hombre de América y no como lo que fue: una mujer para quien la pasión por la política constituyó el motivo fundamental de su existencia, antes y después del libertador.

${ }_{21}$ Como referido anteriormente, esta elegia de Neruda foi base para o argumento de Walter Márquez a respeito da inexistência dos restos mortais de Manuela Sáenz em Paita.
} 
ni dónde estaba ahora

el polvo de sus huesos.

Arriba iban los cerros amarillos,

secos como camellos,

en un viaje en que nada se movia,

en un viaje de muertos,

porque es el agua

el movimiento,

el manantial transcurre.

el rio crece y canta,

y allí los montes duros

continuaron el tiempo:

era la edad, el viaje inmóvil

de los cerros pelados,

y yo les pregunté por Manuelita,

pero ellos no sabian,

no sabian el nombre de las flores.

Al mar le preguntamos,

al viejo océano.

El mar peruano

abrió en la espuma viejos ojos incas

y habló la desdentada boca de la turquesa (NERUDA, 1972, p. 16-18).

Mais recentemente, Aleyda Quevedo Rojas, conterrânea de Manuela, dedicou o livro Dos encendidos (2017) 22 aos amores de Sáenz e Bolivar. Na obra, Quevedo Rojas se exime de falar das aventuras histórico-revolucionárias de Manuela e Bolivar e se concentra na relação entre ambos, desde o primeiro encontro em Quito até os instantes finais dela, em Paita:

Soy una mujer que amó

y encontró la libertad

aunque luego perdió

l libertad y a su amor

Una mujer en un campo de arena y agua

Con un diamante en el pecho
Que nadie logró quebrar

Y solo un hombre logró retener

Soy Manuela Sáenz

Nunca tuve miedo

estoy vieja pero no temo

esta agonía de 26 años

que no ha logrado meterme pánico

Alucinada

con el corazón abierto al cielo

espero la muerte

vestida de soledad

pura en mi locura

preguntándome

en que parte de la dimensión de la muerte

debo buscarme mi bien amado Simón (QUEVEDO ROJAS, 2017, p. 299).

Apesar de se pautar pelos sentimentos de Manuela, como vemos no excerto de "Desde Paita", a poeta avança consideravelmente para além do que tange à paixão amorosa entre Sáenz e Bolivar. Ao criar uma biografia poética dos amantes, Quevedo Rojas intertextualiza as cartas trocadas entre os apaixonados e o Diario de Paita $^{23}$ de Manuela e propõe um diálogo nem sempre conciliador entre os amantes. Como diz Curbelo, a relação está "sempre marcada pela precariedade, pela falta de comunicação, pela satisfação efêmera da carne que leva a uma insatisfação perene do espírito, um paradoxo que só pode ser resolvido quando a putinha do rubor gelado resolve a batalha entre água e fogo, entre corpo e alma" (CURBELO, 2017, p. 23, tradução nossa). ${ }^{24}$ Com isso, dentre as obras analisadas, com risco de estar incorrendo em um excesso, pode-se dizer que Aleyda Quevedo Rojas é, talvez, quem conseguiu, até o momento, abster-se da mitificação que coloca Manuela como amante ou como parceira de guerra de Bolivar para vê-la como uma e outra concomitantemente. Sobretudo,

\footnotetext{
22 A primeira publicação ocorreu em 2008. Em 2016, Quevedo Rojas compilou toda a sua obra poética no livro Cierta manera de luz sobre el cuerpo.

23 O Diario de Paita é formado por apontamentos pessoais de Manuela Sáenz durante seu exilio em Paita, Perú, após a morte de Simón Bolivar. A descoberta do livro teve grande repercussão, mas sua veracidade é amplamente questionada e cada vez mais estudiosos veem o Diario como um apócrifo.

24 Do original: Siempre marcada por la precariedad, por la incomunicación, por la efímera satisfacción de la carne que conduce a une perenne insatisfacción del espiritu, paradoja que solo alcanza a resolverse cuando la putilla del rubor helado dirime la querella entre agua y fuego, entre cuerpo y alma.
} 
esta Manuela tem uma voz que ama, que se queija, que reivindica, que sente falta, que se diz.

Nesta trajetória das obras selecionadas a respeito de Manuela Sáenz, nota-se o desequilibrio frequente entre a apresentação dela e a de Simón Bolivar. A crítica a esse desequilibrio não consiste em desejar a elevação de Sáenz em detrimento ao papel que Bolivar efetivamente exerceu como herói latino-americano. A questão levantada diz respeito à imagem da mulher que também se destacou, mas que, nas biografias, aparece ou secundada ou romantizada, mantendo a personagem, ainda hoje, entre extremos que submetem a mulher ao domínio do privado e do silêncio. Nesse sentido, vale a pena retomar a obra de Van Hagen, a fim de avaliar o papel da manipulação das memórias.

\section{Um resgate questionável}

Conforme assinalado anteriormente, neste estudo, Victor Van Hagen percebeu o logro sofrido pela biografia de Manuela Sáenz, sistematicamente ignorada pelos pesquisadores. Van Hagen seguiu o caminho contrário, talvez de modo temerário. Ele selecionou cuidadosamente quais aspectos da vida de sua personagem ele gostaria de destacar. A palavra "personagem" assume especial conotação aqui, pois é assim que o autor a coloca diante do leitor: ficcionalizada. De acordo com Lander (2016), o propósito de Van Hagen era desmitificar Bolivar e, com isso, dar à Manuela o devido lugar na História:

Quando Simon Bolivar foi metamorfoseado em semideus pelas mesmas pessoas que dez anos antes o haviam execrado, Manuela Saénz, segundo os historiadores, desejou que eles abrissem espaço para o mito. Todos os detalhes de sua vida foram oficialmente suprimidos, os documentos que a mencionavam desapareceram e seus últimos vinte anos foram vividos na obscuridade em Paita (VAN HAGEN, 1952, p. 302, tradução nossa). ${ }^{25}$

Para atingir seu intento, no entanto, Von Hagen não cai na cilada de desmerecer o heroísmo de Bolivar. O que faz, sim, é evitar adjetivações grandiloquentes e idealizações a respeito das ações do herói. Por outro lado, conforme assegura Lander (2016), apresenta vários documentos a respeito de Manuela sem que as fontes sejam apresentadas. Ou seja, Von Hagen constrói um discurso a respeito de Sáenz que se vale de interpretações pessoais e de situações que a colocam em um arcabouço, a princípio, ficcional. Por exemplo, é Van Hagen o responsável por anunciar o famoso encontro entre Melville e Manuela, em Paita, no ano de 1841. Evidências posteriores comprovam que o barco baleeiro Acushnet nunca aportou em Paita durante o periodo em que o escritor inglês fez parte da tripulação. Lander, contudo, observa o valor metafórico da situação:

Mas o mais relevante desse encontro hipotético é seu claro valor metafórico. Essa conexão revela um paralelo interessante entre a vida de Manuela e a do próprio Herman Melville, que. como a quitenha, conhecia uma glória que o desertou. Von Hagen, deixando as portas abertas para especulações, dá ao leitor a oportunidade de reconhecer Melville e Manuela, à sombra das aventuras do capitão Ahab. Todos perseguindo uma obsessão do tamanho da baleia branca. Em vida, Melville perseguia uma glória literária ilusória; Manuela perseguia o sonho bolivariano da Gran Colombia. Ambas as empresas, como no caso do capitão Ahab, terminaram em derrota. A conexão Melville-Manuela, embora seja um ato de reconhecimento do valor da quitenha, é também um gesto revelador de seu valor como personagem. Melville era a carta de apresentação de uma mulher de uma cultura diferente para o público anglo-saxão. Uma mulher que passou quase um século ignorada pela história. Uma mulher que, como Melville, teria que esperar muitos anos para ser redescoberta (LANDER, 2016, p. 164). ${ }^{26}$

\footnotetext{
25 Do original: When Simon Bolivar was metamorphosed into a demigod by the very people who ten years before had execrated him, Manuela Saenz, it was willed by the historians, had to go to make way for the myth. All details of her life were officially suppressed, documents which mentioned her disappeared, and her own last twenty years were lived in obscurity in Paita.

26 Do original: Pero lo más relevante de ese hipotético encuentro es su claro valor metafórico. Dicha conexión desvela un interesante paralelo entre la vida de Manuela y la del propio Herman Melville quien como la quiteña conoció una gloria que lo desertó. Von Hagen, al dejar el mismo las puertas abiertas para la especulación, le brinda al lector la oportunidad de reconocer en Melville y Manuela, la sombra de las aventuras del capitán Ahab. Todos persiguiendo una obsesión tan grande como la ballena blanca. Melville en vida persiguió una esquiva gloria literaria, Manuela persiguió el sueño bolivariano de la Gran Colombia. Ambas empresas, como en el caso del Capitán Ahab, terminaron con la derrota. La conexión Melville-Manuela si bien es un acto de reconocimiento al valor de la quiteña, es también un gesto revelador del valor de ésta como personaje. Melville fue la tarjeta de presentación de una mujer de una cultura diferente para el público anglosajón. Una mujerque pasó casi un siglo ignorada por la Historia. Una mujer que, como Melville, tendria que esperar muchos años para ser redescubierta.
} 
Apesar de The four seasons of Manuela apresentar falta de rigor investigativo, continua sendo um material de estudos bastante representativo e com destacada recepção leitora. O fato de Van Hagen preterir a História pela história sinaliza, em certa instância, o papel do biógrafo que tem menos compromisso com a verdade do que o historiador. Para Lander (2016), nós, como leitores de biografias, estamos à mercê do autor, pois não temos acesso às fontes consultadas e a confiança no lido se baseia no pacto estabelecido no momento em que tomamos o texto nas mãos. Esse acordo não permite questionar o narrador. A biografia, assim, funciona como um sistema fechado construido a partir da habilidade de o biógrafo convencer o leitor, graças a sua habilidade retórica e literária (LANDER, 2016, p. 162). Com isso, The four seasons torna-se uma ficção ${ }^{27}$, ao mitificar Manuela, desmontando a própria autoridade histórica.

Se por um lado, a conceituação de biografia é problematizada, permitindo sua legitimação pelo viés da ficção, de outra parte, o gênero possibilita a construção mítica em torno de " $L a$ Generala" personagem, sobretudo levando-se em consideração o evidente encanto de Van Hagen por ela. As razões para isso são compreensiveis. Manuela é uma personagem fascinante, não somente por seu papel na Revolução, como pelo caráter altivo e determinado. Isso, porém, não resolve o problema da batalha das memórias envolvendo a vida, as ações e a personalidade de Manuela Sáenz, a libertadora de si mesma.

Os estudos feministas tiveram influência indelével na revisão biográfica de Manuela. Grillo atribui à Teresa de La Parra, no início dos anos de 1930, a retomada do mito, e Vilalta destaca os estudos feministas dos anos de 1960. Teresa de la Parra (1889-1936) é uma das vozes venezuelanas mais expressivas e sua obra literária é marcada pela reflexão e questionamentos sobre o mundo que a cerca. Buscando material para ministrar conferências sobre mulheres extraordinárias, depara-se com Manuela a quem chama de hija de La Revolución e de mujer de acción:

\begin{abstract}
A figura da senhora Manuelita é extremamente interessante, não só pelo seu lado pitoresco, mas porque representa, quando bem analisada, o caso do protesto violento contra a servidão tradicional da mulher a quem só é permitido como porvir, a porta nem sempre aberta do casamento. Mulher de ação, não podia suportar nem o engano, nem a comédia de um falso amor. Filha da revolução, não escutou mais do que a verdade e a direito de legítima defesa. Era a mulher aprés guerre da independência. [...] Carregando com orgulho seu título de Libertadora até a velhice, D. Manuelita representa a típica mulher forte. Autônoma e rebelde, ela mesma fez seu código moral e, dentro dele, foi consistente e fiel até a morte. Alguns acharão paradoxal esta afirmação tão contrária à opinião geral e haverá quem se escandalize. Mas aquele que, estando na miséria, for capaz de renunciar à herança de prestar culto a uma memória, que atire a primeira pedra (GRILLO, 2015, p. 75, tradução nossa). ${ }^{28}$
\end{abstract}

Para La Parra, Manuela é o exemplo perfeito de feminismo. Na vida privada, foi capaz de fugir do convento, abandonar o marido, unir-se a Bolivare abrir mão da herança de Thorne. Na vida pública, foi uma cidadã e revolucionária ativa na história do seu país. Em ambos os espaços, sempre uma personagem que rompe, ainda hoje, com quaisquer categorizações ou estereótipos femininos. A partir de La Parra, afirma Grillo, abriu-se um novo caminho para a produção biográfica-narrativa a respeito de Sáenz, desde Rumazo González (1944) até o de Van Hagen (1952), possivelmente o livro mais conhecido, traduzido e citado.

\section{Uma batalha de memórias}

Para Ricoeur (2007), a memória é um trabalho contínuo, sempre capaz de se sobrepor a processos pré-estabelecidos: "[...] não temos nada

\footnotetext{
${ }_{27}$ Segundo Lander (2016), alguns estudiosos latino-americanos não denominam The four seasonsof Manuela Sáenz de biografia, mas de romance.

28 Do origninal: La figura de doña Manuelita es en extremo interesante no sólo por su lado pintoresco sino porque representa, si bien se analiza, el caso de la protesta violenta contra la servidumbre tradicional de la mujer a quien sólo se le deja como porvenir la puerta no siempre abierta del matrimonio. Mujer de acción, no pudo sufrir ni el engaño ni la comedia del falso amor. Hija de la revolución, no escuchó más lenguaje que el de la verdad y el del de $r$ recho a la defensa propia. Fue la mujer après guerre de la Independencia. [...] Llevando asi con orgullo hasta la vejez su título de Libertadora, doña Manuelita aparece como el tipo de la mujer fuerte. Personal y rebelde se fabricó ella misma su código de moral y dentro de él fue consecuente y fiel hasta la muerte. Algunos hallarán paradójica esta afirmación tan con-traria a la opinión corriente y habrá quien se escandalice por ella. Pero que aquel que estando en la miseria sea capaz de renunciar a una herencia por rendir culto a un recuerdo que le tire a doña Manuelita la primera piedra.
} 
melhor que a memória para significar que algo aconteceu, se passou antes que declarássemos nos lembrar dela" (RICOEUR, 2007, p. 40). Ela é o recurso para dar significado ao que importa para nós no passado. Mas, não é possivel acreditar que as referências que permanecem sejam fiéis à realidade vivida, pois o esquecimento se constitui como zonas de sombra na região que nos conecta com o que passou antes isso se transforme em memória. Nesse interstício, nascem testemunhos que constituem uma multiplicidade de vozes que defendem determinada memória. Em tal batalha de memórias, as falsas só podem ser desmascarados por uma instância crítica que contraponha diferentes testemunhos. E nem por isso estaremos diante da verdade absoluta. Existem muitas memórias possiveis sobre determinado acontecimento e, por conseguinte, interpretações alternativas (JELIN, 2012, p. 40).

As memórias sobre Manuela Sáenz foram expostas por exploradores, curiosos, biógrafos, historiadores, literatos, cineastas, documentaristas, políticos, acadêmicos, estrangeiros, latinoamericanos, venezuelanos, equatorianos, homens, mulheres. Tantas vozes em torno de uma mulher multifacetada que, por sua vez, traz à tona a diversidade na maneira de pensar o tempo e, consequentemente, de conceituar memória. É o que faz a pesquisa histórica e antropológica. Jelin nos lembra que a Antropologia clássica, na contramão da História, estudava os povos considerados sem história, o que lhes excluia qualquer memória. Tal perspectiva pressupõe um tempo mítico que remete incessantemente a um momento fundacional. No entanto, a performance ritualizada do mito não é estática, pois não se trata de uma a-historicidade, mas de acontecimentos novos que se inserem em estruturas de sentido preexistentes que podem estar apoiadas em mitos.

Pode-se inferir, com certa ousadia, que ocorre uma espécie de estagnação na imagem da mulher, na medida em que o grande mito - herói, libertador, criollo, intelectual etc. - faz retornar ao momento original da nova América. Mas esse ponto de vista interpretativo só é possivel se nos centramos na dimensão do pari passu entre ambos nas biografias sobre Manuela Sáenz e na dificuldade dos biógrafos - independentemente do suporte - de separá-la do mito bolivariano. Ainda que, como dito, a performance ritualizada é dinâmica, a centralização em Bolivar, mesmo no caso de Van Hagen $^{29}$, leva a entendê-lo como uma instituição política e identitária latino-americana. Os fatos do passado, transformados em memórias, que o colocam nesse patamar incluem indelevelmente Manuela Sáenz. Essa indissociabilidade que se concretiza no imaginário coletivo talvez não permita aos biógrafos fazer o descolamento entre a amante guerreira e a mulher que obteve êxitos pessoais e políticos extraordinários.

Os sujeitos de determinada sociedade constroem uma importante variedade de experiências de vida, guardadas na forma de memórias soltas, mais ou menos separadas das que ocorrem no âmbito social. Para Steve Stern (2002), interessa saber como as duas formas de memórias se vinculam e são as próprias pessoas que conectam o individual e o coletivo. Ao fazê-lo, dão um sentido maior ao ocorrido, tendo em vista que tais eventos não são somente pessoais, mas afetam todo o grupo social. Desse modo, a memória individual e a social envolvem as experiências significativas da comunidade, construindo uma espécie de marco - um terceiro tipo de memória social, a emblemática, organizadora, em certa instância, das várias memórias individuais. O resultado é o que comumente denominamos de história oficial ou um monumento representativo de um evento marcante.

No entanto, a fugacidade da memória também se revela na emblemática, na medida em que não se constrói arbitrariamente, ainda que haja interesses, como costuma ocorrer em processos de violência política, principalmente os pautados por ditaduras ou que visem a instaurar um herói adequado para representar determinado episódio. Trata-se, ao contrário, de um processo e, portanto, a intensa rede criada pela cultura de grupos se sobressai, exigindo repercussão e 
aceitação da comunidade, o que evidentemente funda relações complexas e heterogêneas. Dentre os vários critérios que, segundo Stern, fazem emergir as memórias emblemáticas historicidade, autenticidade, amplitude, difusão de memória em espaços públicos - destacamos a encarnação em um referente social convincente ou determinado referente social, simultaneamente concreto e simbólico, que passe a encarnar a memória emblemática, levando as pessoas a identificarem-se com ela.

Nessa linha, chama-se a atenção para o evento de 2011, o livro-homenagem dedicado a Manuela Sáenz por parte do governo equatoriano e venezuelano. A mesma Manuela que, há um século e meio, era suprimida da história daquele pais, é conduzida à condição de heroína, o que coloca em xeque os usos - e abusos - e sentidos da memória:

A memória como construção social narrativa implica o estudo das propriedades do narrador, da instituição que concede ou nega poder e autoriza pronunciar as palavras, uma vez que, como aponta Bourdieu, a efetividade do discurso performativo é proporcional à a autoridade de quem afirma. Implica também prestar atenção aos processos de construção de reconhecimento legítimo, concedidos socialmente pelo grupo a que se dirige (JELIN, 2012, p. 68, tradução nossa). ${ }^{30}$

Conforme pautam os pesquisadores sobre a memória, a necessidade de criar, coletivamente, uma memória emblemática, a fim de articular um sentido maior, define concomitantemente quais as memórias devem permanecer e quais devem ser relegadas ao esquecimento.

\section{Considerações finais}

A escrita deste artigo pautou-se pela angústia de fazer as devidas seleções a respeito do que dizer e do que ler sobre Manuela Sáenz. Não é uma tarefa fácil, principalmente se optamos pela via da biografia, seja histórica ou dramatizada. A história de protagonista se presta perfeitamente ao melodrama, como alguns estudiosos atentos perceberam, mas também à subversão e ao julgamento fácil sobre o feminino. Não são poucos os estudos que afirmam o que outros estudos desmentem. A conferência entre Manuela e Melville talvez seja o maior dos problemas quanto à veracidade. A leitura de uma extensa bibliografia também permite, não sem dilemas, o discernimento entre as informações ligeiras e as pertinentes.

O biógrafo, caso dos responsáveis pelo legado e pela permanência de Manuela Sáenz no imaginário coletivo, se coloca como um testemunho dos feitos. Ele já existe, anteriormente ao que vai narrar, como alguém que tem um efeito sobre o espaço social (ele é o historiador, o literato, o pesquisador etc.). A esse sujeito que tem o poder da fala sobre determinado herói que está silenciado é outorgada - ou ele a si se outorga - uma tarefa, a de revificar. O biografo torna-se o responsável pelas memórias. Ele pode, inclusive, ver-se como alguém imbuído de uma missão autoimposta de restaurar a ordem, caso de Van Hagen. Cada um desses vieses provoca um discurso e, em uma dimensão mais ampla, uma possivel história oficial.

A vida de Manuelita, ou de La Generala, ou de La Coronela, igualmente se problematiza na medida em que temos de decidir, como pesquisadores mas principalmente como leitores -, se seguimos a História ou a ficção. Talvez, depois de ler uma parte infima da extensa biografia de Manuela Sáenz, a grande pergunta seja, paradoxalmente, quem é Manuela Sáenz. Afinal, como alerta Lander (2016), em se tratando de biografia, fazemos, como leitores, um pacto com o biógrafo, podemos eleger a imagem que mais nos aproxima da personagem. Entre tantas memórias, cada uma das narrativas traz um pouco de Manuela Sáenz. Talvez, vê-la através do extenso mosaico biográfico ofereça o melhor retrato dessa mulher.

\footnotetext{
30 Do original: La memoria como construcción social narrativa implica el estudio de las propiedades de quien narra, de la institución que le otorga o niega poder y lo/a autoriza a pronunciar las palabras, ya que, como señala Bourdieu, la eficacia del discurso performativo es proporcional a la autoridad de quien lo enuncia. Implica también prestar atención a los procesos de construcción del reconocimiento legítimo, otorgado socialmente por el grupo al cual se dirige.
} 


\section{Referências}

ÁlVAREZ SAÁ, Carlos. (Recop). Los diarios perdidos de Manuela Sáenz y otros papeles. Bogotá: Fica, 2005

AÑAZCO, Yolanda. Manuela Sáenz, coronela de los ejércitos de la Patria Grande. Quito: Láser, 2005.

ANDRÉ, Nelly. Manuelita, entre mythelitteraire et recithistorique. Revista História e Cultura, Franca/ SP, v. 3, n. 1, p. 232-252, 2014. Disponivel em: https:// www.researchgate.net/publication/290113663_Manuelita_entre_mythe_litteraire_et_recit_historique_Manuelita_entre_o_mito_literario_e_a_narrativa_historica. Acesso em: 10 mar. 2019. https://doi. org/10.18223/hiscult.v3i1.1196

BELLOTTO, Manoel Lelo; Corrêa, Ana Maria Martínez. Bolivar e a luta pela independência da América: ação e pensamento político. In: BELLOTTO, Manoel Lelo; Corrêa, Ana Maria Martínez. Simón Bolivar: política. São Paulo: Ática, 1983. p. 11-20. https://doi. org/10.1590/s0101-90742012000100001

BENJAMIN, Walter, Magia e técnica, arte e politica: ensaios sobre literatura e história da cultura. São Paulo: Brasiliense, 1994.

BRICEÑO, Olga. Manuela Sáenz, la divina loca: biografía novelada. Rio de Janeiro: Livraria H. Antunes, 1967.

CUNHA, Gloria da. La narrativa histórica de escritoras latinoamericanas. Buenos Aires: Corregidor, 2004

CURBELO, Jesús David. Ejercicios para abordar, de soslayo, el tren rojo de la poesia. In: QUEVEDO ROJAS, Aleyda. Cierta manera de la luz sobre el cuerpo: Poesia reunida (1989-2016). Quito: Casa de Cultura Ecuatoriana, 2017. p. 11-28. https://doi. org/10.31819/9783964563255-019

DE SARLO, Giulia. Manuela Sáenz redescubierta, recuperada, reinventada. La figura de la Libertadora entre Historia y Ficción. In: BAJINI, I; PERASSI, E. (ed.). Independencias Hispanoamericanas. Bogotá: Caro y Cuervo, 2013. p. 115-168.

EMBAJADA DE LA REPÚBLICA DEL ECUADOR. Manuela Sáenz: pasado, presente y futuro. Caracas: Ministerio del Poder Popular para las Relaciones Exteriores de Venezuela, 2011.

GRILLO, Rosa María. Manuela Sáenz: antes y después de Bolivar. Cultura Latinoamericana, [S. l.], v. 21, n. 1, p. 65-89, enero/jun. 2015. Disponivel em: https:// editorial.ucatolica.edu.co/ojsucatolica/revistas_ucatolica/index.php/RevClat/article/view/1635/1512. Acesso em: 17 jul. 2019.

HENNES, Heather. Los "diarios perdidos" de Manuela Sáenz y la formación de un ícono cultural. Kipus: Revista Andina de Letras, Quito, n. 26, p. 109-132, 2. sem. 2009.

HIGUERAS, Gonzalo. El último Tallán. Lima: Editorial Atalaya S.R.L., 2017.
HIGUERAS, Gonzalo; MENDONZA, Rudy. Manuela Sáenz: buscando a manuelita en paita. [S. l: s. n.], [2014?]. Reportaje completo. 1 video (47 m 42 s). Publicado pelo canal Juan Samael Azaña Quintero, 31 out. 2014. Disponivel em: https://www.youtube.com/ watch?v=1eAgaOAVOd4. Acesso em: 21 mar. 2019.

JELIN, Elizabeth. Los trabajos de la memoria. Lima: IEP; Instituto de Estudios Peruanos, 2012.

LANDER, Maria-Fernanda. Sujeto nacional y biógrafo extranjero: la primera biografía en inglés sobre Manuela Sáenz. [S. l.: s. n.], 2016. Disponivel em: https://www.academia.edu/27076952/Sujeto_Nacional_y_bi\%C3\%B3grafo_extranjero_la_primera_biograf\%C3\%ADa_en_ingl\%C3\%A9s_sobre_Manuela_S\%C3\%A1enz. Acesso em: 29 jul. 2019. https://doi. org/10.1353/cnf.2016.0004

LÓPEZ, Silvia L. Del discurso amoroso: La correspondencia de Simón Bolivar y Manuela Sáenz. Revista Landa, Florianópolis, v. 6, n. 2, p. 240-251, 2018. Disponivel em: https://repositorio.ufsc.br/handle/123456789/187161. Acesso em: 5 jul. 2019.

LUCKÁCS, Georg. Teoria do romance. Rio de Janeiro: Duas Cidades: Editora 34, 2000.

LUCKÁCS, Georg. 2000. Teoria do romance. São Paulo: Duas Cidades: Editora 34, 2000.

MANUELA Sáenz. Filme. RISQUEZ, Diego; PADRÓN Leonardo. Venezuela: Producciones Guakamaya, 2000. $97 \mathrm{~m}$

MÁRQUEZ, Walter. Lo de Manuelita Sáenz es un fraude con fines electorales. Noosfera XXI: blog. [S. l.], Jul. 2010. p. [1-2]. Disponivel em: http://virgiliotovar. blogspot.com/2010/07/la-insepulta-de-paitaperu. html. Acesso em: 13 maio 2019.

MURRAY, Pamela. For glory and Bolivar: the remarkable life of Manuela Sáenz. Austin: University of Texas Press, 2008

NERUDA, Pablo. La insepulta de Paita: elegía dedicada a la memoria de Manuela Sáenz, amante de Simon Bolivar. In: NERUDA, Pablo. Cantos ceremo-

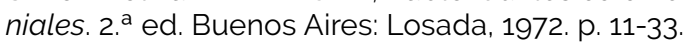
https://doi.org/10.17851/1678-3549.1.1.124-126

QUEVEDO ROJAS, Aleyda. Dos encendidos. In: QUEVEDO ROJAS, Aleyda. Cierta manera de la luz sobre el cuerpo: poesía reunida (1989-2016). Quito: Casa de Cultura Ecuatoriana, 2017. p. 255-299.

RICOEUR, Paul. A memória, a história, o esquecimento. Campinas: Unicamp, 2007.

RUMAZO GONZÁLEZ, Alfonso. Manuela Sáenz, la libertadora del Libertador: biografia. 9. ${ }^{a}$ ed. Ediciones de la Presidencia de la República. Caracas, Venezuela, [s. n.], 1978.

SÁENZ, Jazmín. Simón Bolivar y Manuela Sáenz: la coronela y el Libertador. México, D.F.: L.D. Books, 2010. (Serie Grandes Amores de la Historia). 
STERN, Steve. De la memoria suelta a la memoria emblemática: Hacia el recordar y el olvidar como proceso histórico (Chile, 1973-1998). In: JELIN, E. (comp.). Las conmemoraciones: las disputas en las fechas "in-felices". Madrid: Siglo XXI de España Editores, 2002. https://doi.org/10.17141/iconos.18.2004.3130

TAMARÍS, Raúl \& AÑON, Julio (org.). Las más hermosas cartas de amor entre Manuela y Simón. Caracas: Ediciones de la Presidencia de la República, 2010.

TRIVIÑO ANZOLA, Consuelo. Manuela Sáenz, la libertadora del libertador. Espanha: Centro Virtual Cervantes, [2019?]. Disponivel em: https://cvc.cervantes es/literatura/mujer_independencias/trivino01.htm. Acesso: 11 jul. 2019.

URDANETA, Ramón. Los amores de Simón Bolivary sushijos secretos. 5. ${ }^{a}$ ed. Caracas: Historia y Tradición Grupo Editorial, 2003

URIBE, Juana. Bolivar. Bionovela. 60 episodios. Colombia: Caracol Televisión/NETFLIX, 2019.

VILALTA, María José. Historia de las mujeres y memoria histórica: Manuela Sáenz interpela a Simón Bolivar (1822-1830). European Review of Latin American and Caribbean Studies, Amsterdam, v. 93, Oct. p. 61-78, 2012. Disponivel em: www.red-redial.net/pt/ referencia-bibliografica-64815.htm. Acesso em: 2 jun. 2019. https://doi.org/10.18352/erlacs.8364

VILLANUEVA CHÁVEZ, Victoria. La palabra escrita de Manuela Sáenz. Lima: [s. n]: 2016. Disponivel em: https://issuu.com/victoria_adela/docs/la_palabra_ escrita. Acesso em: 14 mar. 2019.

VON HAGEN, Victor W. The four seasons of Manuela: a biography - the love story of Manuela Saenz and Simon Bolivar. New York: Duell, Sloan \& Pearce Co. 1952. Disponivel em: https://archive.org/details/fourseasonsofman010985mbp/page/n11. Acesso em: 20 maio 2019.

\section{Endereço para correspondência}

Rosane Maria Cardoso

Universidade de Santa Cruz do Sul

Av. Independência, 2293, Prédio 10, sala 1022

Bairro Universitário, 96815-900

Santa Cruz do Sul, RS, Brasil

\section{Rosane Maria Cardoso}

Doutora em Letras pela Pontificia Universidade Católica do Rio Grande do Sul (PUCRS, Porto Alegre, RS, Brasil), professora na Universidade de Santa Cruz do Sul (UNISC), em Santa Cruz do Sul, RS, Brasil. 